\title{
The Practice and Thinking of the Flipped Classroom Model in the E-Commerce Course
}

\author{
Huizhou Zhao \\ College of Information Sciences \\ Beijing Language and Culture University \\ Beijing, China \\ zhaohuizhou@blcu.edu.cn
}

\begin{abstract}
E-Commerce is a comprehensive, multidiscipline, rapidly developing area and we need to excite the students' initiative in the learning process. The flipped classroom model is a suited method. This article introduces our experience of applying four-stage flipped classroom model to our ECommerce course. Comparing to the traditional teaching method, we get the conclusion of the flipped classroom model motivating the students' learning initiative well and the learning effect is mainly affected by the students' study habits and the size of the class.
\end{abstract}

Keywords-E-Commerce course; flipped classroom; motivate learning initiative

\section{INTRODUCTION}

E-Commerce is a course for the 3rd grade undergraduates at the College of Information Sciences in Beijing Language and Culture University. This course is a comprehensive, multidiscipline one, which relates to computer technology, network and communication technologies, business and management. On the other hand, electronic commerce is also an area which is rapidly developing and needs more practice. To help the students achieve good learning effect, we try to excite the students' initiative in the learning process.

The flipped classroom is a new pedagogical method, which needs the students to learn outside the classroom [1] and to participate in more interactive activities, such as problem solving, discussions and debates, in the classroom [2-4]. In the flipped classroom model, the potential value of student-centered learning environments is emphasized, in which students are actively engaged in higher-order tasks and taking charge of their own learning [5,6]. This pedagogical method can motivate the students' learning initiative.

In this article, we introduce our experience of applying the flipped classroom model in the E-Commerce course. The core idea is the four-stage flipped classroom plan which is described in section III.

\section{OVERALL TEACHING DESIGN}

The contents of E-Commerce course include three aspects: (1) the introduction to E-Commerce, (2) ECommerce model which includes B2B, B2C, C2C, new models and mobile E-Commerce, (3) E-Commerce supporting elements which include website development and operational maintenance, E-Commerce security, e-cash and
Internet payment, E-commerce logistics distribution and management. In the overall teaching design, we design the course tasks, teaching process and learning evaluation for helping the students to learn the above contents.

\section{A. Course Tasks}

We set up two kinds of course tasks: theme research and comprehensive practice. Each student is required to complete the above two types of tasks based on team collaboration.

We apply the flipped classroom model to the theme research learning. For each theme, there is a report team which is responsible for detail research learning prior to the in-class sessions of that theme. There are several activities in the classroom, including self-learning guidance for theme learning by the teacher, theme research presentation by the responsible theme research team and theme discussing in the whole class.

Every team finishes the comprehensive practice in the spare time and is required to do in-class oral report in the mid-semester and to submit a written summary report in the end-semester. The teacher and the assistants track and direct the comprehensive practice.

\section{B. Teaching process}

In the whole semester, we follow the "teacher assisting" principle, which means the main function of the teacher is learning instructing and tracking.

At the beginning of the semester, we arrange instruction report to theme research and comprehensive practice after the course introduction. We also train the students to use the learning support platform, including BLCU MOOC system and Weixin platform for the in-class discussion. One week before the in-class theme discussion, the teacher does selflearning guidance for the coming theme in the classroom and distributes out-classroom discussion topics at the BLCU MOOC system. There is one week for the class to do theme learning and exchange ideas on the platform. After the inclass theme representation and discussion, the teacher does oral summary of the theme learning, based on the outclassroom and in-classroom discussion.

\section{Learning evaluation}

The evaluation is emphasized on the procedure of learning. The series of learning tasks take an $80 \%$ part, which is based on the self-learning testing, out-classroom discussion, information collection and in-team discussion for 
theme researching, theme presentation, in-classroom discussion and contribution to the team comprehensive practice. The final article takes a $20 \%$ part.

\section{FOUR-STAGE FLIPPED CLASSROOM PLAN IN THEME LEARNING}

Theme research and discussion are the main ways for theme learning in our E-Commerce course and put the flesh to the flipping classroom model. There are 60 students in our course and are separated in 13 teams. The teacher provides 12 topics for theme research, which cover all the contents of the course. After selecting a topic, a team should re-state the topic in the form of case-based analysis problem and that problem is the object for the team to do theme research. There are two teams selecting the same topic, but that two teams use different cases. Each theme research needs to experience the following activities: spare time research, inclassroom representation and discussion, submitting report.

We apply four-stage flipping classroom plan to every theme learning: in-classroom self-learning guidance, outclassroom self-learning, in-classroom inter-learning and inclassroom feedback.

\section{A. In-classroom Self-learning Guidance}

In-classroom self-learning guidance means the teacher does self-learning guidance report one week before the inclassroom theme discussion. The guidance includes theme learning contents introduction, pointing out learning emphases, difficulties and attention matters of self-learning. The teacher also distributes discussion topic at the BLCU MOOC platform for self-learning discussion.

\section{B. Out-classroom Self-learning}

Out-classroom self-learning means the students have one week to do out-classroom theme self-learning, including reading the text book, reviewing the self-learning guidance handout, collecting materials from the network, sharing ideas and completing self-learning test at the BLCU MOOC platform. The students both participate the discussion topics, which are distributed by the teacher, and set up new topics for discussion in the class if necessary.

For every theme, there is a report team and a main question team. Students in these two teams need to do especial preparation for the in-classroom presentation and discussion. After deciding the case-based problem for theme research, the report team needs to do more information collection, to do in-team discussion and to complete the demonstration materials for the in-classroom presentation. The main question team needs to do especial preparation for the in-classroom discussion. Students in this team need to track the procedure of the report team by viewing the sharing materials. The out-classroom face-to-face activities of the report team and the main question team are assisted by the teaching assistants.

\section{In-classroom Inter-learning}

In-classroom inter-learning includes the activities of presentation by the report team and discussion in the whole class. This stage includes the following activities: (1) theme research presentation, (2) real-time questions during the presentation, (3) real-time questions summary and answer, (4) discussion after presentation. Comparing to the traditional presentation and discussion model, our model encourages students express themselves in time during the presentation, and this can catch the flash points of the audiences.

In order to solve the wireless network instability problem, we set up dual channels for real-time discussion: web-based and Weixin-based. These two channels support well for the audiences expressing their ideas during the presentation.

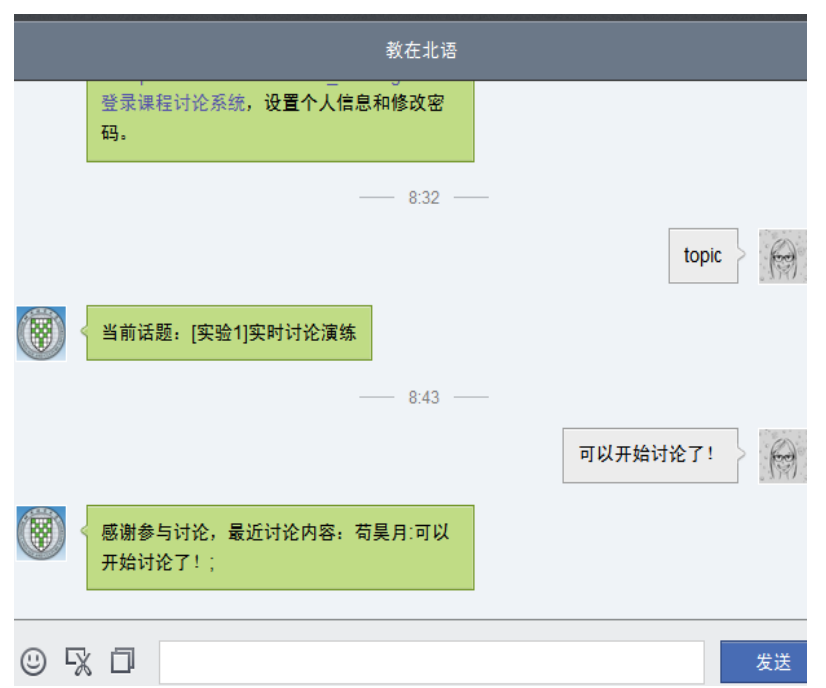

(a)

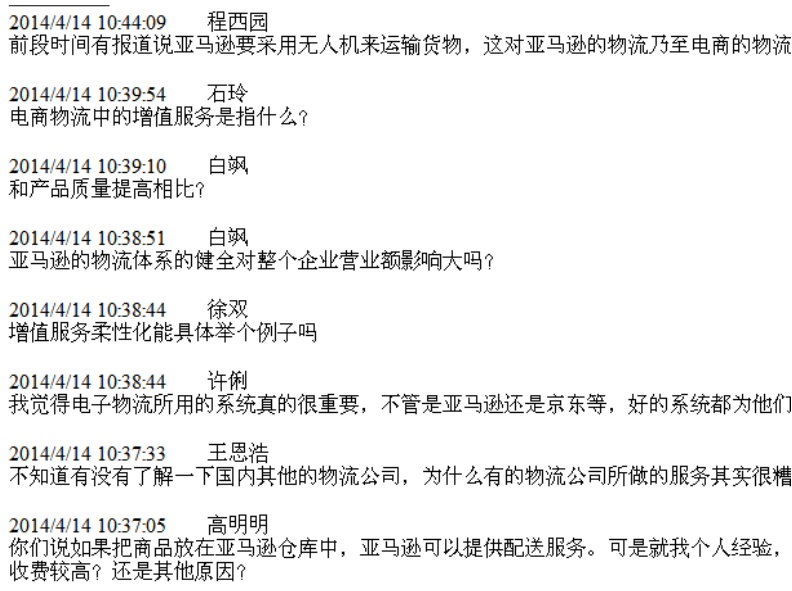

(b)

Figure 1. Real-time discussion by Weixin: (a) mobile phone UI; (b) management UI - discussion list.

\section{In-classroom Feedback}

In-classroom feedback means the teacher doing theme learning summary after the in-classroom discussion. Before the classroom time, the teacher prepares the initial summary handout based on the self-learning test result and the replies to the self-learning discussion topics. In the classroom, the teacher replenishes contents into the summary based on the 
in-classroom presentation, questions and answers. After the class time, the final summary handout is published at BLCU MOOC platform.

\section{LEARNING EFFECTS ANALYSIS}

In the end of the semester, we carried out a survey among all the students for collecting the students' self-evaluation of learning effects. The self-evaluation aspects included course contents, theme research reports, learning materials and experiments. The survey also collected students' opinions on course contents and teaching organization. We sent out 60 questionnaires, 58 were returned, of which 26 questionnaires with real-names. There were 18 returned questionnaires containing subjective opinions, of which 13 questionnaires with real-names. Based on these questionnaires and interview of the previous students, we compare our flippedclassroom based teaching method to the traditional teaching method. The previous E-Commerce course used the traditional teaching method, with which the in-classroom teaching is the main way during the course period. The comparison aspects are followed.

\section{A. Teaching Emphasis}

With the traditional teaching method, the teaching emphasis is course contents.

With the flipped-classroom based teaching method, the course contents are objects for learning, the teaching emphasis is the policy and method to do team-based research learning.

\section{B. Teaching Organization}

With the traditional teaching method, the teacher does inclassroom teaching, and the students do spare time learning if they want.

With the flipped-classroom based teaching method, the students are required to do series of out-classroom tasks, including self-learning each chapter contents, deeply researching a theme. The teacher does in-classroom guidance for students self-learning and summary of theme learning. All the students do inter-learning by presentation and discussion on theme learning.

\section{Classroom Organization}

With the traditional teaching method, the teacher speaks and the students listen in the classroom. The Students are allowed to say something if they want to or are called by the teacher.

With the flipped-classroom based teaching method, more than half the in-classroom time is for the students presenting and discussing. Most students participate in the discussion by their willing. The teacher controls the procedure of the discussion, reminds the negative students to pay attention to the discussion if necessary.

\section{Teaching Preparation}

With the traditional teaching method, teaching preparation is based on course contents.
With the flipped-classroom based teaching method, teaching preparation is based on course contents and the students self-learning which includes test results and online topic discussion.

\section{E. Learning Gains}

With the traditional teaching method, the students get knowledge of E-Commerce related knowledge.

With the flipped-classroom based teaching method, the students not only get knowledge of E-Commerce related knowledge, but also deeply understanding some topics such as the responsible theme or favorite themes. The students also get experience on real problem solving through comprehensive practice.

\section{F. Students Evaluation on Learning Effect of Each Chapter}

With the traditional teaching method, evaluations on different chapters are almost the same.

With the flipped-classroom based teaching method, the students' subjective opinions show that they get deep impression and good learning effect on the responsible theme, but just know the surface of other themes. According to the whole class result, based on the students' impression or self-evaluation learning effect, the top 3 chapters are both chapter 1,3 and 8 . Chapter 1 and 3 are the best 2 inclassroom theme report evaluated by the teacher. Chapter 8 has 2 related theme and 3 responsible teams doing theme research. Therefore, the factors that affect the learning effect of the whole class include the in-classroom theme report quality and the number of students who are responsible for that theme research.

\section{G. Students Evaluation on Study Burden}

With the traditional teaching method, the students feel light in E-Commerce course.

With the flipped-classroom based teaching method, students' feelings are different. Some students think there are so many learning tasks in this course, learning burden is heavy and want to be less required. Some other students who think themselves not active in course study want to be more required.

\section{CONCLUSION}

According to the above comparison, we get the following conclusion: the four-stage flipped classroom teaching plan realized the target of motivating students' learning initiative. We set up more learning tasks and detail requirements, and the students should finish the tasks step by step. This learning procedure directs the students both to get knowledge of the E-Commerce related knowledge and to deeply learn at least one topic in the E-Commerce area. The teaching target of encouraging the students practicing team-based research learning is well done.

On the other hand, the difference between students is obvious. This makes us to realize the limitations of the flipped classroom teaching method.

(1) The successful application of flipped classroom depends on the initiative of students. With this teaching 
method, the teacher guidance is mostly according to the students' performance in self-study and the questions raised by the students. Only the students, who take the initiative to learn and show the learning results, can obtain the valuable guidance from the teacher and learn more.

(2) The effect of the flipped classroom teaching is greatly influenced by the number of students. There are 60 students in our course. Although we set up web-based and Weixinbased double channels for in-classroom discussion, only about 1/3 2/3 students take part in discussion in every class. There are always negative students who did not discuss in class. There also discussion opinions which cannot be replied in class. We think a class with less than 30 students will enhance the overall learning effect by replying in time and correct the negative students' behavior effectively.

\section{ACKNOWLEDGMENT}

BLCU supported project for young researchers program (supported by "the Fundamental Research Funds for the Central Universities") (13YBG46).

\section{REFERENCES}

[1] Fulton K., "Upside Down and Inside Out: Flip Your Classroom to Improve Student Learning". Learning \& Leading with Technology, 39(8), 12-17, 2012.

[2] Zappe S., Leicht R., Messner J., Litzinger T. and Lee H., "'Flipping' the classroom to explore active learning in a large undergraduate course”. Proceedings of the 2009 American Society for Engineering Education Annual Conference and Exhibition, 2009.

[3] Hughes H., "Introduction to flipping the college classroom". In T. Amiel, \& B.Wilson (Eds.), Proceedings from world conference on educational multimedia, hypermedia and telecommunications, pp. 2434-2438, 2012.

[4] Davies R. S., Dean D. L. and Ball N., "Flipping the classroom and instructional technology integration in a college-level information systems spreadsheet course". Educational Technology Research and Development, 61(4), 563-580, 2013.

[5] Hannafin M., Hill J. and Land, S., "Student-centered learning and interactive multimedia: Status, issues, and implication". Contemporary Education, 68(2), pp. 94-99, 1997.

[6] Shea, P., Hayes, S., Smith, S. U., Vickers, J., Bidjerano, T., Pickett, A. et al., "Learning presence: Additional research on a new conceptual element within the Community of Inquiry (CoI) framework.”, The Internet and Higher Education, 15(2), pp. 89-95, 2012. 